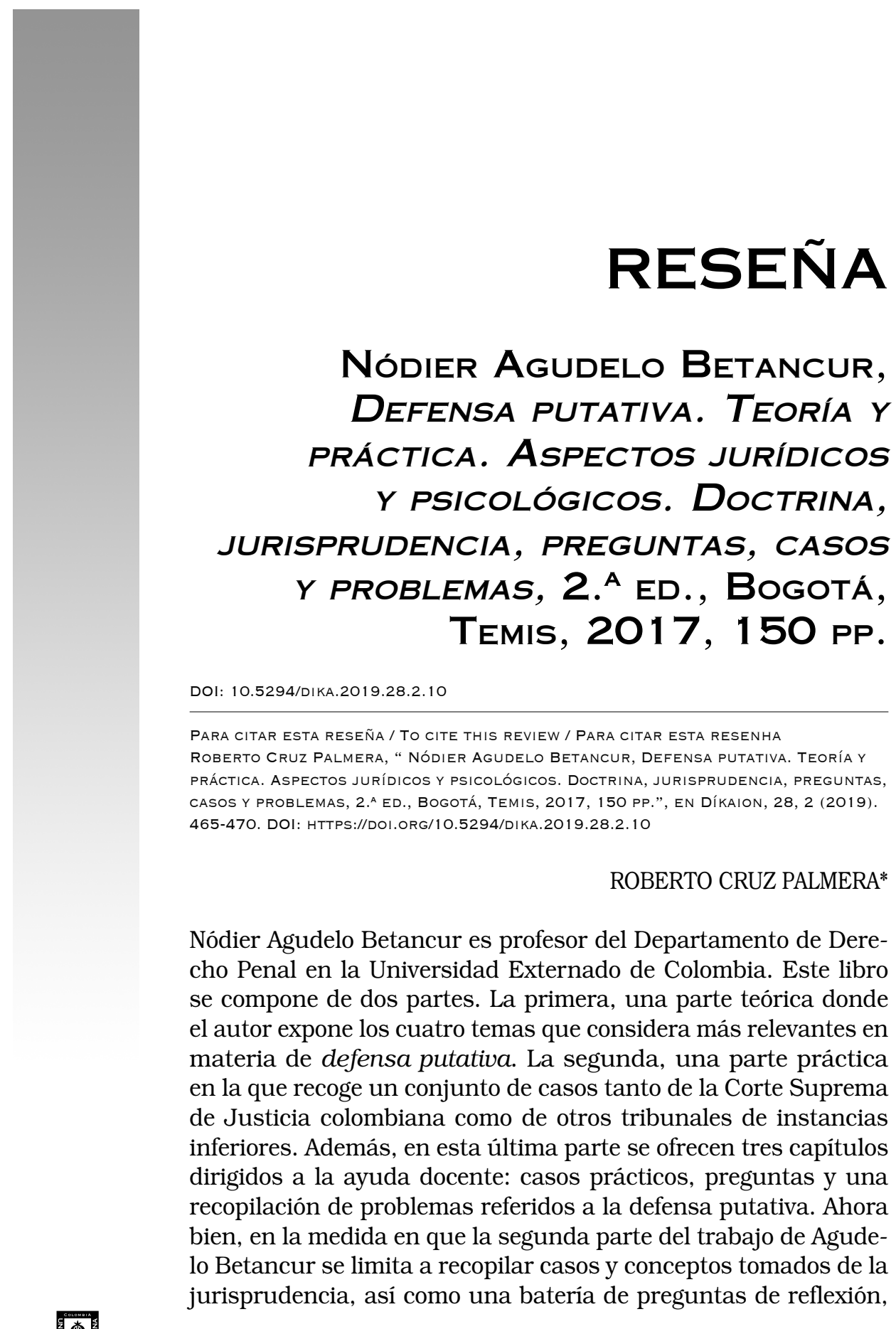

Nódier Agudelo Betancur, PRÁCTICA. ASPECTOS JURÍDICOS Y PSICOLÓGICOS. DOCTRINA, Y PROBLEMAS, 2. A ED., BOGOTÁ, TEMIS, 2017, 150 PP.

$10.5294 / D I K A .2019 .28 .2 .10$

PARA CITAR ESTA RESEÑA / TO CITE THIS REVIEW / PARA CITAR ESTA RESENHA

Roberto Cruz Palmera, "Nódier agudelo betancur, Defensa putativa. Teoría y PRÁCTICA. ASPECTOS JURÍDICOS Y PSICOLÓGICOS. DOCTRINA, JURISPRUDENCIA, PREGUNTAS, CASOS Y PROBLEMAS, 2. A ED., BOGOTÁ, TEMIS, 2017, 150 PP.”, EN DÍKAION, 28,2 (2019). 465-47O. DOI: HTTPS://DOI.ORG/10.5294/DIKA.2019.28.2.10

\title{
ROBERTO CRUZ PALMERA*
}

Nódier Agudelo Betancur es profesor del Departamento de Derecho Penal en la Universidad Externado de Colombia. Este libro se compone de dos partes. La primera, una parte teórica donde el autor expone los cuatro temas que considera más relevantes en materia de defensa putativa. La segunda, una parte práctica en la que recoge un conjunto de casos tanto de la Corte Suprema de Justicia colombiana como de otros tribunales de instancias inferiores. Además, en esta última parte se ofrecen tres capítulos dirigidos a la ayuda docente: casos prácticos, preguntas y una recopilación de problemas referidos a la defensa putativa. Ahora bien, en la medida en que la segunda parte del trabajo de Agudelo Betancur se limita a recopilar casos y conceptos tomados de la jurisprudencia, así como una batería de preguntas de reflexión, 
no me detendré en la descripción de esa parte del libro. Por el contrario, no solo describiré, sino que también expondré algunas críticas a los temas tratados por el autor en la primera parte del trabajo. Finalmente, para la segunda parte, haré una crítica referida al capítulo denominado "Jurisprudencia" (pp. 79-126).

En el capitulo I, "Concepto general y terminologia”, el autor nos acerca a los conceptos básicos tratados en su obra. Entiende por defensa putativa la reacción de un sujeto frente a otro cuando piensa que es atacado. Sin embargo, sabemos que en la realidad no existe ninguna clase de agresión, dado que esta solo se presenta en la mente del sujeto. Se trata de un planteamiento fundado en la defensa putativa como error de prohibición, como causal de inculpabilidad (pp. 3-4). Según Agudelo Betancur, si la defensa putativa no es una causa de justificación, no puede estar legitimada, por tanto, sería injusta. Llegados a este punto aparecen los problemas de la institución que el autor describe con abundantes ejemplos. Afirma que, aunque no estemos ante una legitima defensa, puede generarse una situación de error, tanto vencible como invencible, que impida la culpabilidad, puesto que -en términos objetivos- se producen no pocos supuestos que merecen un ejercicio de ponderación de intereses para cada situación. Seguidamente, Agudelo nos explica la necesidad de adoptar el término defensa putativa en lugar de otras expresiones para entender mejor la institución, pues el término significa putare, esto es: pensar. Y, como sostiene a lo largo del trabajo, la defensa putativa se identifica con una agresión imaginaria, es decir, imaginada por quien en realidad termina por ser un agresor.

En el capítulo II, "Evolución de su concepto en el Derecho penal moderno. La cuestión en Colombia”, para exponer la evolución de la defensa putativa, Agudelo Betancur explica, entre otros asuntos, la equivalencia entre la defensa putativa y la defensa real, y apoya sus argumentos en las tesis de otros autores. Para Agudelo, la diferencia central entre ambas instituciones es que en la legitima defensa "lo putativo" es igual a lo real. Pues, aunque no se cuente con el peligro real, dado que es putativo, todo apunta entonces -al menos en la legislación colombiana- a la posibilidad de plantearse una justificación. Según Agudelo Betancur, si alguien cree que es atacado estaría legitimado para proteger sus intereses de manera racional ante la inexistencia, por ejemplo, de un policía que tendría que defenderlo de la presunta agresión que de manera imaginaria padece. Brevemente, más adelante expone otros temas para describir la evolución en el marco del derecho penal moderno; por ejemplo: la responsabilidad civil derivada de la defensa. Seguidamente expone la defensa putativa como un error de hecho; Nódier Agudelo sostiene que puede entenderse de ese modo, pues lo que falta para configurar el tipo facultativo es la agresión real de un derecho. Dado que el sujeto -que se encuentra en erroractúa con plena intención de defenderse pero, infortunadamente, como se ha dicho, es él, en la realidad, el agresor, esto es desestabilizador del orden jurídico. Por eso se dice que obra en error de hecho, un error en las circunstancias sociales.

Así pues, en el planteamiento de Agudelo Betancur, al encontrarnos ante un tema de error en las circunstancias sociales de hecho debe buscarse una solución conforme a los postulados de esa institución (p. 12). Lo que nos conduce a casos de 
exclusión de la culpabilidad y no de la antijuridicidad, ya que hablamos de error. Luego muestra algunos postulados tanto de la doctrina como de la jurisprudencia colombiana relacionados con el error de hecho (o error en las circunstancias sociales de hecho) como causa de justificación en términos de defensa putativa. En ese marco, al referirse a la jurisprudencia colombiana, la Corte Suprema de Justicia -según Agudelo Betancur- atiende al fenómeno defensa putativa como una causa de inimputabilidad o como causa de justificación. Para dicha Corte, en la defensa putativa se produce el evento de un "agresor", pero "sin conciencia de antijuridicidad", pues se enmarca en un error esencial de hecho que no proviene de negligencia, el cual no siempre debería serle atribuible. En resumen: la acción del sujeto es inconsciente, aunque contraria a derecho. De manera que el sujeto se encontraría en una causa de justificación en sentido negativo (p. 17). Seguidamente, y para reforzar su postura, el profesor Betancur expone algunos pronunciamientos de la Corte Suprema de Justicia que sostienen tal idea. Para recapitular: la posición de la Corte Suprema de Justicia colombiana se basa en que el sujeto no debería responder si está en error, pues no es factible hacerle responsable si obra con ausencia de conocimiento (p. 18).

Uno de los puntos donde el autor reitera su posición personal es que la defensa putativa se basa en un problema de "error de prohibición" (pp. 4, 5, 19, 25, 26, 27, 33, entre otros lugares). En concreto, sostiene que en la defensa putativa: "el sujeto sabe lo que hace, pero cree que su comportamiento está permitido, obra sin conciencia de antijuridicidad: hay error de prohibición" (p. 26). "La defensa putativa, es pues, un caso de error de prohibición y, por consiguiente, representa un problema de culpabilidad" (p. 27).

En el capítulo III, "Problemas particulares”, el autor analiza seis puntos: i) la injusticia imaginaria; ii) la legitima defensa recíproca; iii) la invencibilidad del error; iv) la proporción entre el ataque imaginario y la reacción en la defensa; v) el exceso en la defensa, y vi) la defensa putativa de terceros. No dispongo del espacio necesario para detenerme en todos los problemas trazados en este capítulo, pero creo que el lector que desee adentrase en el contenido podrá apreciar la explicación que brinda Agudelo Betancur. Dicho esto, voy a detenerme -si bien brevemente- en solo tres de los problemas tratados. El primer problema, la injusticia imaginaria. En este particular, se entiende la "injusticia imaginaria" como un error de valoración en la defensa, por lo que la fuente de solución estaría en el error de hecho o en el error de valoración (p. 31). Seguidamente, comenta un ejemplo de error de conocimiento sobre la legitimidad de comportamiento, se refiere a un detective secreto que se rehúsa a mostrar la orden de captura, ante esto el sujeto reacciona pensando que es víctima de un asalto (agresión ilegítima). Esta situación daría lugar a un caso de defensa putativa debido al grado de complejidad de la situación, pues en el contexto citado, el sujeto que reacciona ante el ataque, como podrá suponerse, lo hace "de manera legitima".

El segundo problema, defensa putativa y legitima defensa reciproca. En este punto, Agudelo discute con otros autores acerca de los criterios de solución aplicables en los casos de legitima defensa reciproca frente a la denominada defensa putativa. 
Agudelo llega a la conclusión de que en dichos supuestos, si bien con matices, quien actúa en defensa putativa pone a otro en una causa de justificación (legitima defensa), por lo que se produce la reciprocidad; no obstante, como es sabido, ambas reacciones no están legitimadas (p. 36). En otras palabras, quien actúa en defensa putativa, al suponerse víctima de una agresión, pone al "atacante" en legitima defensa. Sin embargo, el que se cree atacado puede actuar bajo una causal de inculpabilidad; mientras que el individuo que responde al ataque de la defensa putativa lo hace, pero amparado por una causa de justificación.

El tercer problema, exceso en la defensa putativa. La tesis que sostiene en varios lugares es la siguiente: "La diferencia fundamental entre la legitima defensa y la defensa putativa radica en que mientras que en aquella existe ataque real u objetivo, en esta, dicho ataque solo existe en la imaginación del sujeto que reacciona. Pero que ante todos los demás requisitos, hay coincidencia” (p. 56). En ese sentido, el profesor Agudelo describe el problema del exceso en la defensa putativa tanto en la doctrina colombiana como en otros países. Un sector de la doctrina alemana sostiene que los excesos en la defensa putativa se deben sancionar como error de prohibición evitable, lo que atenúa la pena, pues la culpabilidad es minima. De modo que los excesos en defensa putativa se resuelven como un error evitable de prohibición (p. 58). La doctrina colombiana no es unánime ante la posibilidad de determinar el exceso en la defensa putativa. Quienes lo aceptan aseguran que los criterios deben aplicarse de igual manera que en la legitima defensa real, porque en casos en donde un sujeto cree ser víctima de una agresión (defensa putativa) se espera una reacción bajo los mismos parámetros que marca la defensa real; en otras palabras, el baremo tiene que ser exactamente igual que en la legitima defensa. La posición contraria rechaza el anterior planteamiento y afirma que al tratarse de un ámbito psicológico complejo no es posible demandar del sujeto proporción u objetividad en la reacción cuando actúa en un error de hecho. Pues si el error de hecho elimina la culpabilidad ante la ausencia de un tipo que castiga la imprudencia, sería inadecuado admitirlo en un supuesto y rechazarlo en otro. Dicho de otra manera, no parece conveniente admitir una causal de inimputabilidad y rechazarla a la vez (p. 59).

El capítulo IV, "Explicación psicologia de la defensa putativa" es, en mi opinión, uno de los apartados más complejos de este trabajo, pues allí se analiza la defensa putativa pero desde otras ciencias: psiquiatria y psicologia. Agudelo Betancur busca la explicación de la conducta de quien actúa porque cree ser atacado. A su modo de ver, no siempre la defensa putativa se fundamenta en el miedo, pues esta también, aunque no en la mayoría de supuestos, puede mostrarse conservando la presencia del ánimo (p. 65, n. 1). Pero, como hemos anticipado, en la defensa putativa el miedo suele ser un factor determinante. Al tratar otros fenómenos menciona también el de la "catatimia", esto es, una deformación de la percepción del mundo real; este es un factor causal de varias conductas que interfieren en el proceso de asimilación y asociación de ideas del mundo real, el sujeto confunde los datos verídicos del exterior. Siguiendo esta tesis, su autor habla de la ansiedad anticipatoria fundada en el miedo, y se refiere a este como causa perturbadora de la percepción del juicio, factor que altera la realidad. De modo que la ansiedad 
que puede sufrir el sujeto que cree, plenamente, padecer una situación tanto conflictiva como peligrosa, le produce un trastorno. Este es el detonador que anticipa la "reacción defensiva".

Hasta este punto, el planteamiento trazado por Agudelo Betancur, quien elabora un sugestivo análisis de la defensa putativa. Seguidamente, pasaré a efectuar algunas observaciones a propósito de mi lectura.

La primera, no comparto la posición de Agudelo Betancur cuando afirma que la defensa putativa de terceros deba admitirse sin ninguna clase de discusión (cfr. p. 64). Sin bien es cierto que hay supuestos en donde resulta conveniente admitir esta problemática figura, existen no pocos supuestos en donde resulta, cuanto menos, debatible. Piénsese en la protección de bienes jurídicos inmateriales como el honor, pues en no pocos casos es dificil determinar qué clase de conducta resulta idónea para lesionar dichos intereses jurídicos en contextos tan problemáticos como estos. En otras palabras, resulta complejo afirmar el instante a partir del cual el intento es idóneo para lesionar el honor de modo que se configure la creencia errada sobre la necesidad de defender el honor de un tercero. Igualmente, parece discutible la defensa putativa de terceros ante una agresión que no es de carácter penal, sino civil. Además, considero que no está del todo claro admitir dicha "defesa" de un bien individual cuando se afectan intereses generales o sociales.

La segunda, el tema de legitima defensa -en el que se enmarca esta investigación-, como se sabe, resulta sumamente extenso, por eso, con el fin de hacerlo accesible, es entendible que el autor se muestre partidario de acotar la investigación de este trabajo centrando sus planteamientos en determinados aspectos, como lo hemos mostrado en esta reseña. Sin embargo, a mi juicio, la decisión no puede suponer, de ninguna manera, una selección tan estricta de la bibliografia utilizada en este trabajo (pp. 143-147). De ese modo, el autor deja a un lado no pocos monografistas tanto colombianos como extranjeros. Además, tratándose de una nueva edición, no se contienen adendas en el trabajo referidas a la discusión existente en la materia, o sea, materiales para la reconstrucción de concepciones o matizaciones del autor respecto a la primera edición.

La tercera, en cuanto a los aspectos formales del texto, estimo necesario hacer una objeción que atañe estrictamente a la casa editorial. Me refiero a la corrección de estilo. Veo necesario, por no decir forzoso, por parte del editor, tratándose de una segunda edición de esta obra, hacer una revisión mesurada y detenida de cara a los aspectos formales del trabajo para evitar erratas que podrían salvarse con facilidad.

La cuarta objeción está dirigida a la segunda parte del texto. Creo que el lector del libro echará en falta un reajuste de la jurisprudencia citada. Casi nadie dudaría del criterio de selección adoptado por Agudelo al recoger la doctrina jurisprudencial; sin embargo, todas las sentencias han sido dictadas entre los años 1936 y 1982. De este modo, deja fuera un interesante grupo de casos que podrían 
ayudarnos a ilustrar mejor el fenómeno de la defensa putativa mediante casos recientes, pero también a exponer la evolución de la jurisprudencia colombiana (por ejemplo, mediante los siguientes fallos de la Corte Suprema de Justicia, Sala Penal: SP19224-2017, NR. 74716, M. P. Patiño Cabrera; SP1478-2015, NR. 42273, M. P. González Muñoz; SP1437-2014 NA. 40, M. P. Bustos Martínez; entre otras). Por esos motivos, considero oportuno contar con referencias posteriores al año 1982.

Las observaciones a este trabajo no restan mérito alguno a la aportación que ofrece el autor, por el contrario, creo que nos invitan a mantener vivo el debate en esta materia en nuestro país. Para finalizar, considero que este texto refleja la continuidad en la investigación realizada por el autor en temas tan discutidos como la legitima defensa. 